\title{
Continuing mortality of vultures in India associated with illegal veterinary use of diclofenac and a potential threat from nimesulide
}

\author{
Richard J. Cuthbert, Mark A. Taggart, Mohini Saini, Anil Sharma \\ Asit Das, Mandar D. Kulkarni, Parag Deori, Sachin Ranade \\ Rohan N. Shringarpure, Toby H. Galligan and Rhys E. Green
}

\begin{abstract}
The collapse of South Asia's Gyps vulture populations is attributable to the veterinary use of the non-steroidal anti-inflammatory drug (NSAID) diclofenac. Vultures died after feeding on carcasses of recently-medicated animals. The governments of India, Nepal and Pakistan banned the veterinary use of diclofenac in 2006. We analysed results of 62 necropsies and 48 NSAID assays of liver and/or kidney for vultures of five species found dead in India between 2000 and 2012. Visceral gout and diclofenac were detected in vultures from nine states and three species: Gyps bengalensis, Gyps indicus and Gyps himalayensis. Visceral gout was found in every vulture carcass in which a measurable level of diclofenac was detected. Meloxicam, an NSAID of low toxicity to vultures, was found in two vultures and nimesulide in five vultures. Nimesulide at elevated tissue concentrations was associated with visceral gout in four of these cases, always without diclofenac, suggesting that nimesulide may have similar toxic effects to those of diclofenac. Residues of meloxicam on its own were never associated with visceral gout. The proportion of Gyps vultures found dead in the wild in India with measurable levels of diclofenac in their tissues showed a modest and non-significant decline since the ban on the veterinary use of diclofenac. The prevalence of visceral gout declined less, probably because some cases of visceral gout from 2008 onwards were associated with nimesulide rather than diclofenac.
\end{abstract}

Richard J. Cuthbert* and Toby H. Galligan RSPB Centre for Conservation Science, Royal Society for the Protection of Birds, Sandy, Bedfordshire, UK

Mark A. TAgGart, Environmental Research Institute, University of the Highlands and Islands, Castle St, Thurso, UK

Mohini Saini, Anil Sharma and Asit Das Centre for Wildlife Conservation, Management \& Disease Surveillance, Indian Veterinary Research Institute, Izatnagar, Uttar Pradesh, India

Mandar D. Kulkarni, Parag Deori, Sachin Ranade and Rohan N. Shringarpure Bombay Natural History Society Mumbai, India

Rhys E. Green† (Corresponding author) Conservation Science Group, Department of Zoology, University of Cambridge, Downing Street, Cambridge, CB2 3EJ, UK. E-mail r.green@zoo.cam.ac.uk

${ }^{\star}$ Also at: Wildlife Conservation Society, Goroka, Eastern Highlands Province, Papua New Guinea

$\dagger$ Also at: RSPB Centre for Conservation Science, Royal Society for the Protection of Birds, Sandy, Bedfordshire, UK

Received 7 January 2015. Revision requested 4 February 2015.

Accepted 3 March 2015. First published online 20 May 2015.
Veterinary use of nimesulide is a potential threat to the recovery of vulture populations.

Keywords Diclofenac, environmental pollution, Gyps, meloxicam, nephrotoxicity, nimesulide, non-steroidal antiinflammatory drug, vulture

To view supplementary material for this article please visit http://dx.doi.org/10.1017/So03060531500037X

\section{Introduction}

Dopulations of three species of Gyps vultures endemic to L South Asia fell by more than $97 \%$ between the early 1990 s and 2007 (Prakash et al., 2003, 2007, 2012), leading to their being categorized as Critically Endangered in the IUCN Red List (BirdLife International, 2014). Research has established that veterinary use of diclofenac, a non-steroidal anti-inflammatory drug (NSAID), was the principal cause of this collapse in vulture numbers (Oaks et al., 2004; Green et al., 2004, 2007; Shultz et al., 2004). Diclofenac is nephrotoxic at low doses to all species of Gyps vultures tested (Oaks et al., 2004; Swan et al., 2006a). Residues of the drug were found in carcasses of domesticated ungulates available to vultures in India (Green et al., 2007; Taggart et al., 2007, 2009) and vultures were exposed when they consumed carcasses of ungulates treated shortly before death (Oaks et al., 2004; Green et al., 2006). Post-mortem examination of Gyps vultures killed by diclofenac poisoning in experiments showed extensive visceral gout and necrosis of kidney tissues similar to that seen in a high proportion of vultures found dead in the wild (Oaks et al., 2004; Shultz et al., 2004; Meteyer et al., 2005; Swan et al., 2006a). Bans on the veterinary use of diclofenac have been in force since 2006 in India, Pakistan and Nepal, and since 2010 in Bangladesh. The safety to Gyps vultures of meloxicam, an alternative veterinary NSAID, has been established experimentally (Swan et al., 2006b; Swarup et al., 2007). In India the proportion of ungulate carcasses contaminated with diclofenac fell by about half within 4 years of the introduction of the ban (Cuthbert et al., 2014). In association with this decrease in diclofenac prevalence, the rate of decline of Gyps vulture populations in India, Nepal and Pakistan has slowed (Jamshed et al., 2012; Prakash et al., 2012), as has the decline in two other vulture species, 
red-headed vulture Sarcogyps calvus and Egyptian vulture Neophron percnopterus, which may also be affected by diclofenac (Galligan et al., 2014).

Here we report the findings of necropsies of dead vultures collected in India during 2000-2012, which includes periods before and after the diclofenac ban in 2006. We re-evaluate the previously observed perfect association of visceral gout with diclofenac and other NSAIDs by comparing necropsy results with measurements of the concentrations of nine NSAIDs in liver and/or kidney. We evaluate changes over time in the prevalence of visceral gout and NSAID contamination in carcasses of vultures found dead in the wild.

\section{Methods}

\section{Collection of vulture carcasses}

Carcasses of vultures were collected from July 2000 to April 2012 in nine states of India (Assam, Gujarat, Haryana, Himachal Pradesh, Jharkhand, Madhya Pradesh, Maharashtra, Rajasthan and Uttarakhand), extending from the western to the eastern extremes of the country. We report here only results for specimens for which the year of collection was known and results of necropsy, NSAID assay or both were available. A total of 62 vultures were examined at necropsy for visceral gout (one cinereous vulture Aegypius monachus, one Eurasian griffon vulture Gyps fulvus, three Himalayan griffon vultures Gyps himalayensis, 17 long-billed vultures Gyps indicus and 40 oriental white-backed vultures Gyps bengalensis). Liver and/or kidney samples from 48 vultures were assayed for NSAIDs (one A. monachus, one G. fulvus, three G. himalayensis, $10 \mathrm{G}$. indicus and $33 \mathrm{G}$. bengalensis). Carcasses of 47 vultures (1 A. monachus, 1 G. fulvus, 3 G. himalayensis, 10 G. indicus and 32 G. bengalensis) were assessed for both gout and NSAIDs. No NSAID assays were available for seven G. indicus and eight $G$. bengalensis with necropsy results, and one G. bengalensis with an NSAID assay did not have a necropsy result. Vulture carcasses were collected by staff of the Bombay Natural History Society and volunteers, local conservation NGOs and individuals. Two carcasses of G. bengalensis were obtained as a result of special efforts to collect and treat the large numbers of birds killed and injured by collisions with kite strings during the annual kite-flying festival in the city of Ahmedabad (Gujarat), but the others were found opportunistically, dead or dying in the field. After their population decline became apparent, vultures in India were strictly protected under Schedule I of the Wildlife Protection Act (1972), which requires permits before live or dead specimens can be collected. This restriction influenced both the number of carcasses obtained and the distribution of collection localities. Our study included all 23 vulture carcasses collected in India for which data were reported by Shultz et al. (2004).

\section{Necropsies of vulture carcasses and assessment of visceral gout}

Detailed necropsy examinations were undertaken by trained veterinarians and field biologists who followed a standard protocol (Cunningham et al., 2003). This included external and internal visual examination for gross abnormalities, and the collection of liver and/or kidney tissues for subsequent NSAID residue analysis. Where possible, morbid tissues fixed in $10 \% \mathrm{NBF}$ were processed by a conventional technique to obtain $4 \mu \mathrm{m}$ thick paraffin embedded sections (Luna, 1972). The sections stained with routine hematoxylin and eosin stain were examined microscopically for pathological changes associated with nephrotoxicity. De Galantha stain was employed for demonstration of urate crystals. Images of representative changes were documented. Samples of kidney and/or liver were removed and frozen for NSAID assays.

In some cases, when carcasses were found in remote locations or where trained personnel were not available, full necropsies could not be performed and less detailed examinations were conducted in the field. We consider these examinations, together with the detailed post mortems, sufficient for the detection of the presence or absence of visceral gout based upon observation of white crystals of uric acid deposited on the surfaces of organs such as the liver (see Oaks et al., 2004 and Swan et al., 2006a for illustrations). In reviewing the post-mortem reports, we found two cases of white deposits on internal organs, like those seen in gout, in which this was considered at the time to be possibly due to an unidentified fungal infection in one case and candidiasis (a specific fungal infection) in another. In both cases, fungal infection was not confirmed by microscopy. In the case of the bird with suggested candidiasis, subsequent histopathological examination of the kidney revealed severe gout nephrosis. This suggested that white deposits observed on macroscopic examination had been misidentified as fungal infection. We therefore judged that gout had been mistakenly identified as fungal disease in both cases and reassigned both as having visceral gout.

\section{Measurement of NSAID residues}

Samples of frozen liver and kidney (c. $0.5 \mathrm{~g}$ ) were thawed and weighed (to $\pm 1 \mathrm{mg}$ ) into new glass test tubes and homogenized with $2 \mathrm{ml}$ of HPLC grade acetonitrile. This mixture was then centrifuged at $1000 \mathrm{~g}$ for 5 minutes and the supernatant filtered using disposable PTFE syringe filter units of 0.45 micron. The filtered extract was stored in LC vials at $-20^{\circ} \mathrm{C}$ until analysis. Samples collected up until June 2004 were analysed for diclofenac only by LC-ESI/MS 
(liquid chromatography-electrospray ionization mass spectrometry) using an Agilent 1100 LC and 1946D MS, following methods in Taggart et al. (2007). The limit of quantification (LOQ) for this technique (back-calculated to wet tissue concentration) was $0.01 \mathrm{mg} \mathrm{kg}^{-1}$. Samples collected after June 2004 were analysed for nine different veterinary NSAIDs (carprofen, diclofenac, flunixin, ibuprofen, indometacin, ketoprofen, meloxicam, naproxen and nimesulide) that were selected based on their potential risk to avian species, presence within pharmacies in India and likelihood of entering the veterinary sector in the region (Taggart et al., 2009; Cuthbert et al., 2011). They were analysed by LC-ESI/MS in negative ion mode (utilizing a C18 column) following methods described in Taggart et al. (2009). LOQ values for these nine NSAIDs were 0.005-0.02 $\mathrm{mg} \mathrm{kg}^{-1}$ (see Supplementary Table $\mathrm{S}_{1}$ in Taggart et al., 2009). The LOQ for diclofenac was the same (0.01 $\mathrm{mg} \mathrm{kg}^{-1}$ ) in the analyses conducted before and after June 2004. Of the 48 carcasses for which diclofenac measurements were made, values were available for both liver and kidney for 37 carcasses, liver only for eight carcasses and kidney only for three carcasses.

\section{Statistical analysis}

The statistical significance of associations between the presence of gout and the detection of diclofenac residues in liver and/or kidney was assessed using the Fisher exact test for a $2 \times 2$ contingency table (Siegel \& Castellan, 1988). The twotailed exact probability was calculated for the observed outcome under a null hypothesis of no association.

We estimated trends over time in the prevalence of diclofenac residues in the liver and/or kidney and the prevalence of visceral gout in vultures by logistic regression analysis, (Crawley, 2007) with the presence/absence of diclofenac contamination or the presence/absence of gout as binary dependent variables and calendar year of collection as an independent variable. It was necessary to allow for species and age class in these analyses because previous studies have indicated that the prevalence of both gout and diclofenac contamination of Gyps vultures in the Indian subcontinent vary with those variables. Both prevalences tend to be higher in $G$. bengalensis than in $G$. indicus (Green et al., 2004; Shultz et al., 2004) and higher in adults than immatures (Gilbert et al., 2002; Green et al., 2004). For example, in a large sample of $G$. bengalensis found dead in Pakistan, the prevalence of visceral gout increased progressively with age, being $13 \%$ in nestlings, $19 \%$ in fledglings, $63 \%$ in subadults and $80 \%$ in adults (Gilbert et al., 2002).

The proportions of carcasses of different Gyps species changed over time. For example, after 2004 a larger proportion of the carcasses examined were of $G$. bengalensis rather than G. indicus (Table 1). Given that the prevalence of gout and diclofenac tended to be higher in G. bengalensis than in
G. indicus when the species are compared during the same period (see above), ignoring the change over time in species composition in the regression analysis would bias the estimated trend to be more positive (less negative) than it should be.

The proportion of adult vultures in the sample examined was slightly higher after 2004 than before (Table 1 ), and this would tend to bias the trend in the opposite direction. To allow for these differences we fitted multiple logistic regression models with the main effects of species ( $G$. himalayensis, G. indicus and G. bengalensis) and age class (nestling, immature [i.e. juvenile and sub-adult] and adult) each included as three-level factors in addition to time (collection year) as a continuous variable.

We excluded from the logistic regression models the results for the single specimens of A. monachus and G. fulvus because the small sample size for these species did not allow us to fit reliable statistical models of the effects of species differences. We also excluded results for two Gyps bengalensis carcasses whose recovery was associated with a kite festival (see above). Carcasses whose age class was not recorded were also excluded (six carcasses from the gout dataset and two carcasses from the diclofenac dataset).

We expected that the prevalence of diclofenac contamination and visceral gout would decline with increasing time during this period, based upon independent information on the downward trend in diclofenac contamination of ungulates (Cuthbert et al., 2014). Hence, we used one-tailed $t$-tests in these analyses to assess the statistical significance of trends over time. We plotted the expected proportions from the models against time for adult $G$. bengalensis and adult G. indicus.

\section{Comparison of the decline in diclofenac prevalence in} vulture carcasses with the decline expected from surveys of diclofenac in ungulate carcasses

We calculated the expected probability of death caused by diclofenac per vulture meal $(C)$ in mid 2005 and the annual survival rate of adults in the absence of diclofenac using the simulation model of a vulture population described by Green et al. (2004). We obtained values of $C$ and survival that gave a value for the annual rate of population decline for $G$. bengalensis in India equal to the value observed at that time (population multiplication rate $\lambda=0.520$; Green et al., 2004) and a value for the proportion of dead adult $G$. bengalensis with diclofenac in mid 2005 equal to that from the multiple logistic regression fitted to post-mortem data (see preceding section), which was $85.2 \%$. We then estimated $C$ for mid 2009 by reducing the mid 2005 estimate by $66 \%$, which is the change in this parameter estimated for the 4 years between mid 2005 and mid 2009 from the surveys of diclofenac concentrations in liver samples of ungulate carcasses available to vultures in India by Cuthbert et al. 
TABLE 1 Co-occurrence of visceral gout and residues of NSAIDs in carcasses of wild Gyps vultures collected in India during $2000-2011$. Results are shown separately for a period when assays were only performed for diclofenac (2000-2004) and a later period (2005-2011) when carprofen, flunixin, ibuprofen, indometacin, ketoprofen, meloxicam, naproxen and nimesulide were also assayed. For these additional drugs, only residues of nimesulide and meloxicam were detected. Numbers of nestlings, immatures, adults and birds of unknown age, respectively, are shown in brackets.

\begin{tabular}{|c|c|c|c|c|c|c|}
\hline Species & Gout & Diclofenac & Nimesulide & Meloxicam & $\begin{array}{l}\text { Nimesulide } \\
\text { \& meloxicam }\end{array}$ & No NSAID \\
\hline \multicolumn{7}{|l|}{ 2000-2004 } \\
\hline \multirow[t]{2}{*}{ G. fulvus } & Yes & 0 & & & & 0 \\
\hline & No & 0 & & & & $1(0,1,0,0)$ \\
\hline \multirow[t]{2}{*}{ G. himalayensis } & Yes & 0 & & & & 0 \\
\hline & No & 0 & & & & $1(0,1,0,0)$ \\
\hline \multirow[t]{2}{*}{ G. indicus } & Yes & $6(0,5,1,0)$ & & & & 0 \\
\hline & No & 0 & & & & $3(0,2,1,0)$ \\
\hline \multirow[t]{2}{*}{ G. bengalensis } & Yes & $7(0,3,4,0)$ & & & & 0 \\
\hline & No & 0 & & & & $4(1,1,2,0)$ \\
\hline \multirow[t]{2}{*}{ All species } & Yes & $13(0,8,5,0)$ & & & & 0 \\
\hline & No & 0 & & & & $9(1,5,3,0)$ \\
\hline \multicolumn{7}{|l|}{$2005-2011$} \\
\hline \multirow[t]{2}{*}{ G. fulvus } & Yes & 0 & 0 & 0 & 0 & 0 \\
\hline & No & 0 & 0 & 0 & 0 & 0 \\
\hline \multirow[t]{2}{*}{ G. himalayensis } & Yes & $1(0,1,0,0)$ & 0 & 0 & 0 & 0 \\
\hline & No & 0 & 0 & 0 & 0 & $1(0,1,0,0)$ \\
\hline \multirow[t]{2}{*}{ G. indicus } & Yes & 0 & 0 & 0 & 0 & 0 \\
\hline & No & 0 & 0 & 0 & 0 & $1(0,1,0,0)$ \\
\hline \multirow[t]{2}{*}{ G. bengalensis } & Yes & $11(2,1,8,0)$ & $3(0,1,1,1)$ & 0 & $1(0,0,1,0)$ & 0 \\
\hline & No & 0 & $1(0,0,1,0)$ & $1(0,0,0,1)$ & 0 & $4(1,3,0,0)$ \\
\hline \multirow[t]{2}{*}{ All species } & Yes & $12(2,2,8,0)$ & $3(0,1,1,1)$ & 0 & $1(0,0,1,0)$ & 0 \\
\hline & No & 0 & $1(0,0,1,0)$ & $1(0,0,0,1)$ & 0 & $6(1,5,0,0)$ \\
\hline
\end{tabular}

TABLE 2 Concentrations $\left(\mathrm{mg} \mathrm{kg}^{-1}\right.$ ) of nimesulide and meloxicam and the presence of visceral gout in all six carcasses (of G. bengalensis) in which either or both of these drugs was detected. Other NSAIDs (diclofenac, carprofen, flunixin, ibuprofen, indometacin, ketoprofen and naproxen) were assayed in all these birds but none was detected.

\begin{tabular}{|c|c|c|c|c|c|c|c|}
\hline \multirow[b]{2}{*}{ Age class } & \multirow[b]{2}{*}{ State } & \multirow{2}{*}{$\begin{array}{l}\text { Collection } \\
\text { year }\end{array}$} & \multicolumn{2}{|c|}{ Nimesulide $^{*}$} & \multicolumn{2}{|c|}{ Meloxicam ${ }^{\star}$} & \multirow{2}{*}{$\begin{array}{l}\text { Visceral } \\
\text { gout? }\end{array}$} \\
\hline & & & Liver & Kidney & Liver & Kidney & \\
\hline Adult & Gujarat & 2008 & 0.309 & 2.753 & $<$ LOQ & $<$ LOQ & Yes \\
\hline Juvenile & Gujarat & 2010 & 0.297 & 0.014 & $<\mathrm{LOQ}$ & $<\mathrm{LOQ}$ & Yes \\
\hline Adult & Jharkhand & 2010 & 0.010 & 0.014 & $<\mathrm{LOQ}$ & $<\mathrm{LOQ}$ & No \\
\hline Unknown & Gujarat & 2010 & $<$ LOQ & $<$ LOQ & 0.187 & 0.684 & No \\
\hline Unknown & Gujarat & 2011 & 0.156 & 0.689 & $<\mathrm{LOQ}$ & $<\mathrm{LOQ}$ & Yes \\
\hline Adult & Gujarat & 2011 & 0.573 & 1.459 & 0.019 & 0.028 & Yes \\
\hline
\end{tabular}

$*<\mathrm{LOQ}$, below the limit of quantification of the assay

(2014). We used the method given by Green et al. (2004) to calculate the expected proportion of deaths of adult G. bengalensis caused by diclofenac in mid 2009 from this reduced mid 2009 value of $C$. We obtained confidence limits for this expected proportion from the bootstrap confidence limits for the change in expected death rate per meal given by Cuthbert et al. (2014; see their Table 2). We performed a significance test of the difference between the expected proportion of deaths of adult $G$. bengalensis caused by diclofenac in mid 2009 based upon vulture necropsies and the estimate of the same quantity derived from the surveys of diclofenac in ungulate livers. To do this we generated lists of 10,000 bootstrap estimates of the proportions of vultures with diclofenac for each of the two methods. We aligned the two randomly-ordered lists, calculated the absolute difference between values for each pair of bootstrap replicates and took the proportion of replicates in which the difference had the opposite sign to that observed in the real data to be the probability of observing by chance a difference as large as or larger than that obtained from the original calculations. 


\section{Results}

\section{Prevalence of visceral gout}

Visceral gout was not present in either of the single A. monachus or G. fulvus carcasses examined. In the other three species the overall proportions with gout were $33 \%$ for G. himalayensis ( $1 / 3), 53 \%$ for $G$. indicus $(9 / 17)$ and $73 \%$ for G. bengalensis (29/40).

\section{Co-occurrence of visceral gout and NSAID residues in the liver and/or kidney}

During the period 2000-2004, when diclofenac was the only NSAID being measured, diclofenac residues were present in liver and/or kidney tissue in all Gyps vulture carcasses in which visceral gout was identified, and in none of the carcasses with no gout (Table 1). This perfect association between diclofenac and visceral gout is highly significant (Fisher exact test $\mathrm{P}<0.0001$ ). In the later period, 20052011, in which other NSAIDs were also assayed in addition to diclofenac, all Gyps vulture carcasses with diclofenac residues also had visceral gout and no carcasses without gout had diclofenac. However, four of the 16 carcasses with gout did not have measurable levels of diclofenac, but did have residues of other NSAIDs (Table 1). All four of these carcasses had nimesulide in both the liver and kidney and one of them had meloxicam, as well as nimesulide, in both tissues. Of eight carcasses without gout, one had very low residues of nimesulide and one had residues of meloxicam (Table 1). Hence, during 2005-2011 the perfect association between diclofenac and gout found in the earlier period became weaker, though it remained statistically significant (Fisher exact test $\mathrm{P}=0.0013$ ). A logistic regression analysis of the 29 vulture carcasses with gout, in which the presence/absence of diclofenac was the binary dependent variable and year of collection was the independent variable, suggested a tendency for the proportion of vulture carcasses with gout that had no diclofenac residues to increase over time, but this trend was not statistically significant $\left(t_{27}=1.48, \mathrm{P}=0.15\right)$.

\section{Concentrations of NSAIDs in liver and kidney of vultures}

In the 37 vulture carcasses for which diclofenac assays were performed for both liver and kidney, diclofenac was detected above the limit of quantification in both tissues in all 17 cases in which it was detected in either tissue, and was below the limit of quantification in both tissues in the remaining 20 cases. In the 17 cases with diclofenac above the LOQ in both tissues, there was a significant positive correlation between the concentrations in liver and kidney $(r=$ $0.663, t_{15}=3.43, \mathrm{P}=0.003$, Supplementary Fig. S1). The arithmetic means of the concentrations of diclofenac in liver and kidney in this subset of individuals were similar and not significantly different (liver, mean $0.181 \mathrm{mg} \mathrm{kg}^{-1}$, range $0.010-0.797 \mathrm{mg} \mathrm{kg}^{-1}$; kidney, mean $0.253 \mathrm{mg} \mathrm{kg}^{-1}$, range $0.010-0.872 \mathrm{mg} \mathrm{kg}^{-1}$; Wilcoxon signed ranks test, $\mathrm{P}=0.124)$.

In the five vulture carcasses in which nimesulide was detected, levels were above the limit of quantification in both liver and kidney (Table 2). There was a weak and nonsignificant positive correlation between the nimesulide concentrations in the liver and kidney $\left(r=0.491, t_{3}=0.97\right.$, $\mathrm{P}=0.402$, Supplementary Fig. S2). Four of the five carcasses with measurable residues of nimesulide had visceral gout. The carcass with nimesulide and no gout had low concentrations of nimesulide near to the limit of quantification in both tissues, whilst the four birds with gout had considerably higher concentrations in one or both tissues (Table 2). In the two vulture carcasses in which meloxicam was detected, it was above the limit of quantification in both liver and kidney. In one of these carcasses there was visceral gout, but the concentration of meloxicam was very low in both liver and kidney whereas the concentration of nimesulide in both tissues was very high. The other carcass with meloxicam had high concentrations of the drug in both liver and kidney but no sign of visceral gout (Table 2). Meloxicam was the only NSAID detected in this bird.

\section{Changes over time in the prevalence of diclofenac and} visceral gout

Logistic regression analysis of the trend in the prevalence of diclofenac in liver and/or kidneys of vultures indicated a decline that was close to statistical significance (Fig. 1a). In a multiple regression model with effects of species and age accounted for, the logarithm of the odds of a vulture carcass having a measurable level of diclofenac declined by 0.2019 per year $\left(1 \mathrm{SE}=0.1246, t_{36}=1.620\right.$, one-tailed $\left.\mathrm{P}=0.057\right)$. The proportion of adult $G$. bengalensis expected from the regression model to have a measurable level of diclofenac fell from $85 \%$ in the middle of 2005 , just before the diclofenac ban, to $72 \%$ four years later in mid 2009 (Fig. 1a). For G. indicus, the equivalent change was from 77 to $59 \%$.

Logistic regression analysis of the trend in the prevalence of visceral gout indicated a non-significant decline at a slower rate than that for diclofenac (Fig. 1b). In a multiple regression model with effects of species and age accounted for, the logarithm of the odds of a vulture carcass having gout declined by 0.1289 per year $\left(1 \mathrm{SE}=0.1038, t_{36}=1.242\right.$, one-tailed $\mathrm{P}=0.110$ ). The proportion of adult $\mathrm{G}$. bengalensis expected from the regression model to have gout fell from $88 \%$ in the middle of 2005 to $82 \%$ four years later in mid 2009 (Fig. 1b). For G. indicus the equivalent change was from 61 to $48 \%$. 

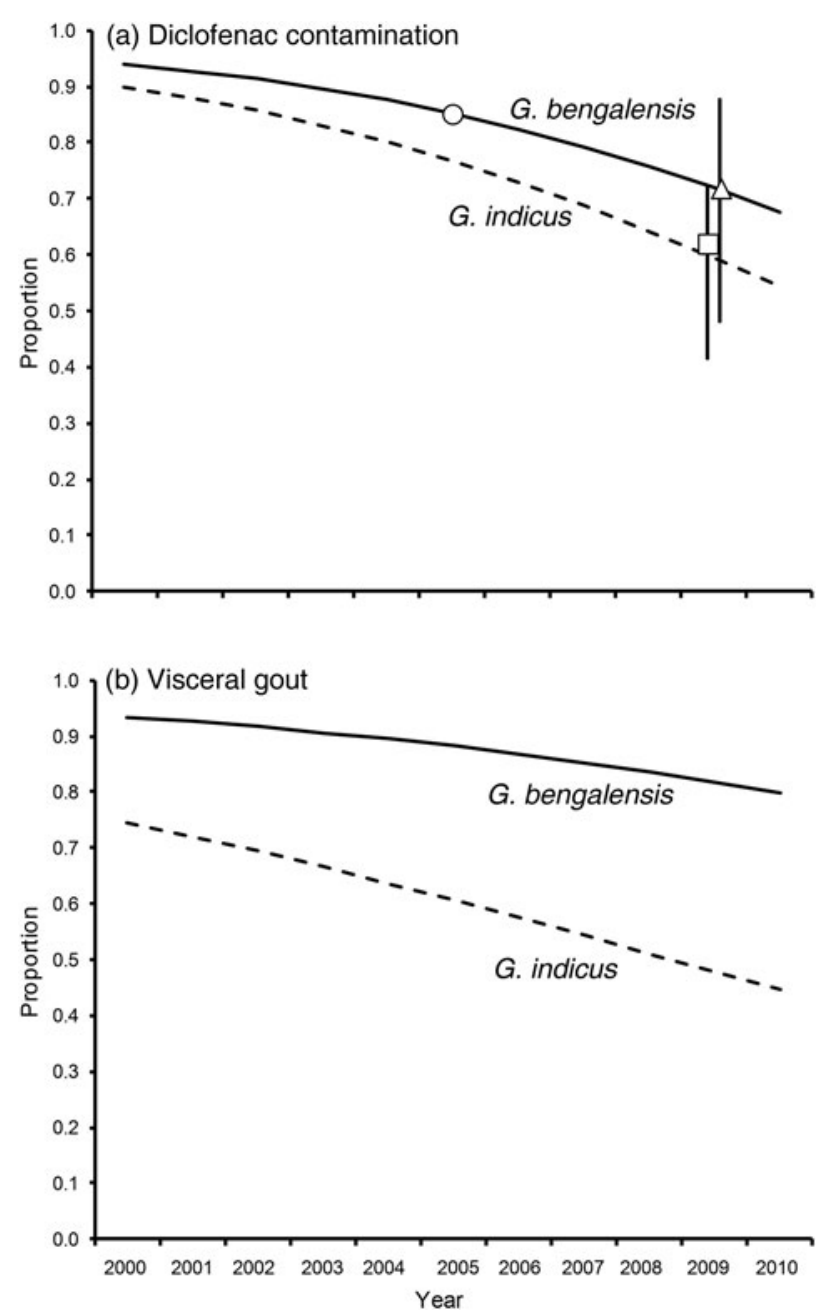

FIG. 1 (a) Proportions of carcasses of wild adult Gyps bengalensis and $G$. indicus contaminated with diclofenac, in relation to the year of collection. Curves represent expected values from a logistic regression model that included the main effects of species, age class and year. Symbols show the expected proportions of adult $G$. bengalensis contaminated with diclofenac in mid 2005 (circle) and mid 2009 (triangle) from the data from vulture carcasses, and the expected proportion of adult G. bengalensis deaths caused by diclofenac in mid 2009 (square) based upon the results of surveys of diclofenac contamination of carcasses of domesticated ungulates. Vertical lines are $95 \%$ confidence limits. (b) Proportions of carcasses of wild adult $G$. bengalensis and $G$. indicus with visceral gout, in relation to the year of collection. Curves represent expected values from a logistic regression model that included the main effects of species, age class and year.

Comparison of the decline in diclofenac prevalence in vulture carcasses with the decline expected from surveys of diclofenac in ungulate carcasses

The expected vulture death rate per meal estimated from surveys of diclofenac residues in liver samples from ungulate carcasses declined by $66 \%$ in the 4 years between mid 2005 and mid 2009 (see Table 2 of Cuthbert et al., 2014). This change in expected death rate per meal, when used in the vulture population model of Green et al. (2004; see Methods), gave an expected proportion of deaths of adult G. bengalensis caused by diclofenac in mid 2009 of $62.0 \%$ (95\% confidence limits $41.5-72.2 \%$ ). The estimated proportion of adult $G$. bengalensis carcasses with diclofenac in mid 2009 derived from the logistic regression model of vulture necropsy results was $71.9 \%$ (95\% confidence limits $48.2-$ $87.5 \%$ ) whereas the same proportion derived from the surveys of diclofenac in ungulate carcasses was $62.0 \%$, if it is assumed in both cases that the proportion of vulture carcasses with diclofenac in mid 2005 was $85.2 \%$ (Fig. 1a). The decline in the proportion of vulture carcasses with diclofenac derived from vulture necropsies was smaller than that derived from diclofenac surveys of ungulate carcasses $(85.2-71.9 \%$ cf. 85.2-62.0\%, respectively). However, the difference between the estimates derived from the two methods does not approach statistical significance (bootstrap $\mathrm{P}=0.201$ ).

\section{Discussion}

Our results indicate that diclofenac remained a significant cause of mortality for India's vultures and that the drug has continued to kill birds long after the 2006 regulations to prevent its veterinary use. The proportion of Gyps vultures found dead in the wild in India that had measurable levels of diclofenac in their tissues showed only a small and non-significant decline in the 5 years following the ban on the veterinary use of diclofenac covered by our study. The estimated size of the decline was broadly consistent with an independent estimate based upon measurements of the change in the prevalence and concentration of diclofenac in carcasses of domesticated ungulates available to vultures (Cuthbert et al., 2014). Continued mortality of vultures in India caused by diclofenac after the ban is consistent with the continued availability of the drug in pharmacies. Based upon surveys conducted between November 2007 and June 2010 in eleven Indian states, Cuthbert et al. (2011) reported that diclofenac formulated for non-veterinary use was offered for sale for veterinary use in $36 \%$ of pharmacies that sold any type of NSAID.

All vultures with measurable diclofenac in liver and/or kidney had visceral gout and this association was highly statistically significant. Wild Asian Gyps vultures that died with visceral gout and with measurable diclofenac in their tissues in our study had similar concentrations of diclofenac in the kidney to those that died in similar circumstances in the study of Oaks et al. (2004). Means and ranges were similar in our study of wild $G$. bengalensis and $G$. indicus carcasses from India $\left(\right.$ mean $=0.253 \mathrm{mg} \mathrm{kg}^{-1}$, range $=0.010-0.872 \mathrm{mg} \mathrm{kg}^{-1}$ ), the study of Oaks et al. (2004) of wild G. bengalensis carcasses from Pakistan (mean $=0.271 \mathrm{mg} \mathrm{kg}^{-1}$, range $=$ $0.064-0.642 \mathrm{mg} \mathrm{kg}^{-1}$ ) and the study of Oaks et al. (2004) 
of captive G. bengalensis that died after experimental administration of meat from water buffalo or goat given a veterinary dose of diclofenac shortly before death (mean $=0.388 \mathrm{mg} \mathrm{kg}^{-1}$, range $\left.=0.070-0.906 \mathrm{mg} \mathrm{kg}^{-1}\right)$. We therefore consider that diclofenac was likely to have been the cause of death of all of the vultures reported in the present study in which the drug was detected at above the limit of quantification.

The estimated decline in the prevalence of visceral gout in Gyps vultures found dead in India was smaller than that for diclofenac prevalence, and did not approach statistical significance. This may be because cases of visceral gout that were not associated with the presence of diclofenac in liver and/or kidney tissues began to occur from 2008 onwards. Four G. bengalensis with gout collected during 2008-2011 had no measurable diclofenac, but all had high concentrations of nimesulide in the liver and/or kidney. One of these carcasses also contained meloxicam residues but at concentrations so low that involvement of meloxicam in the death of the bird is unlikely. Another G. bengalensis carcass had a very low concentration (near LOQ) of nimesulide in both liver and kidney and no visceral gout. Hence, wild vultures in India are being exposed to nimesulide. Exposure at a high level is associated with visceral gout and death. Reddy et al. (2006) suggested that nimesulide is likely to be safe for vultures, based upon a comparison of the toxicity of nimesulide and diclofenac to domestic fowl Gallus domesticus. However, there are large differences in the toxicity of NSAIDs among bird species (Cuthbert et al., 2006), so the safety of nimesulide in domestic fowl cannot be taken to indicate its safety to distantly-related vultures.

Nimesulide is legally approved for veterinary use in India and was offered for sale for this purpose in $48 \%$ of pharmacies that sold any type of NSAID in surveys conducted during 2007-2010 in eleven Indian states (Cuthbert et al., 2011). The prevalence of nimesulide in pharmacies was particularly high in Gujarat, where it was offered for sale for veterinary use in $80 \%$ of shops visited ( 28 out of 35 shops; R.J. Cuthbert, unpubl. data). It is therefore notable that all four vultures with both nimesulide residues and visceral gout were collected from Gujarat. However, there is little evidence of nimesulide in carcasses of domesticated ungulates in India. Taggart et al. (2009) did not find any nimesulide residues in liver samples from 1,488 ungulate carcasses collected between April and December 2006. After including further samples collected up until July 2010 (total $n=3,150$ ), only three ungulate carcasses with low $\left(<0.04 \mathrm{mg} \mathrm{kg}^{-1}\right)$ levels of nimesulide were found ( $0.1 \mathrm{mg} \mathrm{kg}^{-1}$; M.A. Taggart, unpubl. data).

Comparison of the time to maximum plasma concentration $\left(t_{\max }\right)$ and elimination half-life $\left(T_{1 / 2}\right)$ of nimesulide in cattle following intramuscular injection shows that its pharmacokinetics are broadly similar to those of diclofenac (EMEA, 2003; Mahapatra et al., 2009). Hence, the elimination of nimesulide in cattle is unlikely to be much more rapid than for diclofenac. To date, the liver has been the only organ routinely sampled in surveys of NSAIDs in ungulate carcasses in India (Taggart et al., 2007, 2009; Cuthbert et al., 2014). Nimesulide concentrations in ungulate livers may be unusually low relative to other tissues. Alternatively, the exposure pathway for vultures may involve sources of carrion that have not been surveyed, such as poultry waste. These questions should be addressed through further field sampling and experiments to study tissue distribution of nimesulide in ungulates.

Another NSAID found in vulture carcasses was meloxicam, which is the only drug established by experiment to be of low toxicity to Gyps vultures and other scavenging birds (Swan et al., 2006b; Cuthbert et al., 2007; Swarup et al., 2007). One vulture carcass with visceral gout had a low concentration of meloxicam and a high concentration of nimesulide in liver and kidney tissues, as described above. Another vulture carcass had a high concentration of meloxicam in liver and kidney and no trace of any other NSAID, and it had no evidence of gout. The cause of death of this bird was recorded to be diphtheroid enteritis. Therefore our findings are consistent with the safety to vultures of veterinary use of meloxicam indicated by experimental studies on captive birds. However, carcasses of wild vultures should continue to be monitored to check that this is the case under field conditions.

The NSAIDs carprofen, flunixin, ibuprofen, indometacin, ketoprofen and naproxen were not detected in any of the 25 vulture carcasses assayed for them. In experiments on the African vultures Gyps coprotheres and Gyps africanus, ketoprofen has been shown to be nephrotoxic at doses that are likely to be encountered by wild vultures (Naidoo et al., 2010). A wild G. fulvus was recently found dead in Spain with visceral gout associated with high levels of flunixin residues in liver and kidney tissues (Zorrilla et al., 2015). This augments previous evidence from surveys of the therapeutic use of NSAIDs on captive vultures in zoos, rehabilitation centres and other collections (Cuthbert et al., 2007) that flunixin may be nephrotoxic to Gyps vultures. Cuthbert et al. (2007) also found evidence of nephrotoxicity of carprofen in one Gyps vulture. Experiments on captive vultures to measure the toxicity of flunixin and carprofen have not yet been conducted.

Taggart et al. (2009) found that some liver samples from domesticated ungulates available to vultures in India during April-December 2006 contained residues of ibuprofen and ketoprofen, but flunixin was not detected (Table 2 in Taggart et al., 2009). In surveys conducted during 20072010 in 11 Indian states by Cuthbert et al. (2011), flunixin was being offered for sale for veterinary use in $7 \%$ of pharmacies that sold any type of NSAID, ibuprofen in $32 \%$ and ketoprofen in $29 \%$. The fact that we did not find residues of these drugs in the sample of 25 vulture carcasses assayed for 
them may reflect the small size of our sample rather than their true absence from vulture carcasses. There is a $5 \%$ probability of our survey finding no contamination with any of these drugs, even if the true prevalence of the drugs in vulture carcasses had been as high as $11 \%\left((1-0.113)^{25}=0.05\right)$.

Our study highlights the continuing threat to Asia's vultures from veterinary use of diclofenac and identifies a new potential threat from nimesulide. Toxicity testing of nimesulide on Gyps vultures is needed to establish whether or not the compound is nephrotoxic. Illegal misuse in the veterinary sector of diclofenac products labelled 'for human use only' is the cause of much of the ongoing threat from that drug and further action to eliminate this has been recommended (Cuthbert et al., 2011). Identification of NSAIDs that are effective on cattle and also safe for vultures at the maximum likelihood exposure level would be valuable for vulture conservation, but so far the only known example of such a drug is meloxicam.

\section{Acknowledgements}

We thank the Ministry of Environment and Forests and the Chief Wildlife Wardens for the states of Assam, Gujarat, Haryana, Himachal Pradesh, Jharkhand, Madhya Pradesh, Maharashtra, Rajasthan and Uttarakhand for permissions, and Kartik Shastri, Ruchi Dave, S. Saravaran, Satya Prakash, Sumantha Ghosh, Puja Basu, Bhrigu Neog and Vibhu Prakash for collecting vulture carcasses. Andrew Cunningham, Romain Pizzi, Yedra Feltrer, Devojit Das, Percy Avari, Jeherul Islam and Devendra Podadhe performed the necropsies. Ian Newton provided useful comments. We gratefully acknowledge financial support and assistance for the project from the Director, Indian Veterinary Research Institute, the UK Government's Darwin Initiative and the Royal Society for the Protection of Birds.

\section{References}

Birdife International (2014) Gyps bengalensis. In The IUCN Red List of Threatened Species v. 2014.2. Http://www.iucnredlist.org [accessed 13 November 2014].

Crawley, M.J. (2007) The R Book. John Wiley \& Sons, Chichester, UK.

Cunningham, A.A., Prakash, V., Pain, D., Ghalsasi, G.R., Wells, G.A.H., Kolte, G.N. et al. (2003) Indian vultures: victims of an infectious disease epidemic? Animal Conservation, 6, 189-197.

Cuthbert, R.J., Dave, R., Chakraborty, S.S., Kumar, S., Prakash, S., RANADE, S.P. \& PRAKASH, V. (2011) Assessing the ongoing threat from veterinary non-steroidal anti-inflammatory drugs to Critically Endangered Gyps vultures in India. Oryx, 45, 420-426.

Cuthbert, R., Pain, D.J., Green, R.E., Swan, G. \& Swarup, D. (2006) Comparative toxicity studies of NSAIDs in birds: a criticism of Reddy et al. Environmental Toxicology and Pharmacology, 23, 254-255.
Cuthbert, R., Parry-Jones, J., Green, R.E. \& Pain, D.J. (2007) NSAIDs and scavenging birds: potential impacts beyond Asia's critically endangered vultures. Biology Letters, 3, 90-93.

Cuthbert, R.J., Taggart, M.A., Prakash, V., Chakraborty, S.S., Deori, P., Galligan, T. et al. (2014) Avian scavengers and the threat from veterinary pharmaceuticals. Philosophical Transactions of the Royal Society B, 369, http://dx.doi.org/10.1098/rstb.2013.0574

EMEA (The European Agency for the Evaluation of Medicinal Products) (2003) Committee for Veterinary Medicinal Products, Diclofenac Summary Report EMEA/MRL/885/ o3-FINAL September 2003. EMEA, London, UK.

Galligan, T.H., Amano, T., Prakash, V.M., Kulkarni, M., Shringarpure, R., Prakash, N. et al. (2014) Have population declines in Egyptian vulture and red-headed vulture in India slowed since the 2006 ban on veterinary diclofenac? Bird Conservation International, 24, 272-281.

Gilbert, M., Virani, M.Z., Watson, R.T., OAks, J.L., Benson, P.C., $\mathrm{KHAN}_{\mathrm{H}}$ A.A. et al. (2002) Breeding and mortality of oriental white-backed vulture Gyps bengalensis in Punjab Province, Pakistan. Bird Conservation International, 12, 311-326.

Green, R.E., Newton, I., Shultz, S., Cunningham, A.A., Gilbert, M., Pain, D.J. \& Prakash, V. (2004) Diclofenac poisoning as a cause of vulture population declines across the Indian subcontinent. Journal of Applied Ecology, 41, 793-800.

Green, R.E., Taggart, M.A., Das, D., Pain, D.J., Sashi Kumar, C., Cunningham, A.A. \& Cuthbert, R. (2006) Collapse of Asian vulture populations: risk of mortality from residues of the veterinary drug diclofenac in carcasses of treated cattle. Journal of Applied Ecology, 43, 949-956.

Green, R.E., Taggart, M.A., Senacha, K.R., Raghavan, B., Pain, D.J., Jhala, Y. \& Cuthbert, R. (2007) Rate of decline of the oriental white-backed vulture population in India estimated from a survey of diclofenac residues in carcasses of ungulates. PLoS ONE, 2(8), e686.

Jamshed, M., Chaudhry, I., Ogada, D.L., Malik, R.N., Virani, M.Z. \& Giovanni, M.D. (2012) First evidence that populations of the Critically Endangered long-billed vulture Gyps indicus in Pakistan have increased following the ban of the toxic veterinary drug diclofenac in South Asia. Bird Conservation International, 22, 389-397.

LunA, L.G. (1972) Manual of Histologic Staining Methods of the Armed Forces Institute of Pathology, 3rd edition. W.B. Saunders, Philadelphia, USA.

Mahapatra, L., Sahoo, G.R., Panda, M.K. \& Parija, S. (2009) Pharmacokinetic profile of nimesulide in bovine calves. Journal of Bioequivalence \& Bioavailability, 1, 121-126.

Meteyer, C.U., Rideout, B.A., Gilbert, M., Shivaprasad, H.L. \& OAKs, J.L. (2005) Pathology and proposed pathophysiology of diclofenac poisoning in free-living and experimentally exposed oriental white-backed vultures (Gyps bengalensis). Journal of Wildlife Diseases, 41, 707-716.

Naidoo, V., Wolter, K., Cromarty, D., Diekmann, M., Duncan, N., Meharg, A.A. et al. (2010) Toxicity of non-steroidal anti-inflammatory drugs to Gyps vultures: a new threat from ketoprofen. Biology Letters, 6, 339-341.

Oaks, J.L., Gilbert, M., Virani, M.Z., Watson, R.T., Meteyer, C.U., Rideout, B.A. et al. (2004) Diclofenac residues as the cause of vulture population decline in Pakistan. Nature, 427, 630-633.

Prakash, V., Bishwakarma, M.C., Chaudhary, A., Cuthbert, R., Dave, R., Kulkarni, M. et al. (2012) The population decline of Gyps vultures in India and Nepal has slowed since veterinary use of diclofenac was banned. PLoS ONE, 7(11), e49118.

Prakash, V., Green, R.E., Pain, D.J., Ranade, S.P., Saravanan, S., PraKash, N. et al. (2007) Recent changes in populations of resident 
Gyps vultures in India. Journal of the Bombay Natural History Society, 104, 129-135.

Prakash, V., Pain, D.J., Cunningham, A.A., Donald, P.F., Prakash, N., Verma, A. et al. (2003) Catastrophic collapse of Indian white-backed Gyps bengalensis and long-billed Gyps indicus vulture populations. Biological Conservation, 109, 381-390.

Reddy, P.N.C., Anjaneyulu, Y., Sivasankari, B. \& Rao, K.A. (2006) Comparative toxicity studies in birds using nimesulide and diclofenac sodium. Environmental Toxicology \& Pharmacology, 22, 142-147.

Shultz, S., Baral, H.S., Charman, S., Cunningham, A.A., Das, D., Ghalsasi, G.R. et al. (2004) Diclofenac poisoning is widespread in declining vulture populations across the Indian subcontinent. Proceedings of the Royal Society of London B (Supplement), 271, $\mathrm{S}_{458-\mathrm{S}} 46 \mathrm{o}$.

Siegel, S. \& Castellan, N.J. (1988) Nonparametric Statistics for the Behavioral Sciences, 2nd edition. McGraw-Hill, New York, USA.

Swan, G.E., Cuthbert, R., Quevedo, M., Green, R.E., Pain, D.J., Bartels, P. et al. (2006a) Toxicity of diclofenac to Gyps vultures. Biology Letters, 2, 279-282.

Swan, G.E., Naidoo, V., Cuthbert, R., Green, R.E., Pain, D.J., Swarup, D. et al. (2006b) Removing the threat of diclofenac to Critically Endangered Asian vultures. PLoS Biology, 4(3), e66.

Swarup, D., Patra, R.C., Prakash, V., Cuthbert, R., Das, D., Avari, P. et al. (2007) Safety of meloxicam to Critically Endangered Gyps vultures and other scavenging birds in India. Animal Conservation, 10, 192-198.
Taggart, M.A., Senacha, K.R., Green, R.E., Cuthbert, R., Jhala, Y.V., Meharg, A.A. et al. (2009) Analysis of nine NSAIDs in ungulate tissues available to critically endangered vultures in India. Environmental Science and Technology, 43, 4561-4566.

Taggart, M.A., Senacha, K.R., Green, R.E., Jhala, Y.V., Raghavan, B., Rahmani, A.R. et al. (2007) Diclofenac residues in carcasses of domestic ungulates available to vultures in India. Environment International, 33, 759-765.

Zorrilla, I., Martinez, R., Taggart, M.A. \& Richards, N. (2015) Suspected flunixin poisoning of a wild Eurasian griffon vulture from Spain. Conservation Biology, 29, 587-592.

\section{Biographical sketches}

Richard J. Cuthbert did research on the conservation of Asian vultures and seabirds of oceanic islands before moving to the Wildlife Conservation Society. MAR K TAGG AR T studies levels of contamination and the impacts of pollutants on wildlife species. MoH IN I Saini, Anil Sharma and Asit Das conduct research on nutrition and the effects of animal diseases and pollutants on the health of wildlife in India. MANDAR DILIP KULKARNI studies conservation genetics of Gyps vultures. PARAG DEORI works as a veterinarian on the Bombay Natural History Society's vulture programme. SACHIN RANADE works on ex situ conservation and ecology of Gyps vultures and carries out population surveys. ROHAN N. SHRINGARPURE is studying microflora in Gyps vultures. Тову H. Galligan and RHys E. GREen research the conservation of Asian vultures and other bird species. 